\title{
Developing Creativity in Computer Science Initial Teacher Education through Design Thinking
}

\author{
Gemma O'Callaghan \\ School of Science, Galway-Mayo IT, Galway, Ireland
}

\begin{abstract}
Design thinking is a valuable component in teacher education enabling the development of creativity amongst the cohort. Studies have been developed to capture the effects of discipline specific design thinking, however design thinking amongst Computer Science pre-service teachers has not been thoroughly evaluated. Pre-service Computer Science post-primary teachers will need to have the capacity to develop these skills within their initial teacher education programmes. In this paper we propose a design thinking workshop model for use by pre-service teachers to engage and motivate students while covering core CS concepts, using web application development. Computer Science as a subject at post-primary will enable students solve real-world problems through the design and creation of computational artefacts developed using a collaborative human-centred approach.Developing such artefacts requires particular skills, such as creativity and problem-solving and it will be necessary for Computer Science pre-service teachers to use innovative problem-solving approaches when fostering these skills. The paper will present the project implementation along with qualitative and quantitative findings. In particular this paper highlights the pre-service teacher perception of the benefits of design thinking in Computer Science particularly applicability in the domain and increased engagement. This, we argue, is critical in our understanding and important in their initial teacher education.
\end{abstract}

\section{CCS CONCEPTS}

- Applied computing $\rightarrow$ Education; Interactive learning environments.

\section{KEYWORDS}

Computer Science Education, Creativity, Design Thinking

\section{ACM Reference Format:}

Gemma O'Callaghan and Cornelia Connolly. 2020. Developing Creativity in Computer Science Initial Teacher Education through Design Thinking. In United Kingdom \& Ireland Computing Education Research conference. (UKICER '20), September 03, 04, 2020, Glasgow, United Kingdom. ACM, New York, NY, USA, 6 pages. https://doi.org/10.1145/3416465.3416469

\section{(c) (7)}

This work is licensed under a Creative Commons Attribution International 4.0 License. UKICER '20, September 03, 04, 2020, Glasgow, United Kingdom

(C) 2020 Copyright held by the owner/author(s)

ACM ISBN 978-1-4503-8849-8/20/09.

https://doi.org/10.1145/3416465.3416469

\author{
Cornelia Connolly \\ School of Education, National University of Ireland, \\ Galway, Ireland
}

\section{INTRODUCTION}

The introduction of Computer Science at Senior Cycle will change the way Irish schools approach computing and information technology [1-4] - replacing the idea of IT literacy and passive consumers of computing to innovators, creators and designers [4-6]. The National Council for Curriculum and Assessment (NCCA) was formed to lead developments in educational curriculum and assessment and to support the implementation of changes resulting from this work. They are responsible for the development of the curriculum for the subject having conducted a survey into the provision of computer science at post-primary level internationally.

Developing and fostering creativity and problem solving in the learner is a main aim of the Computer Science specification [1]. Aligned with this and in-line with international trends, a framework of 5 key skills has been put forward for the senior cycle, one of those skills is Critical and Creative Thinking .This skill comprises of several elements including "thinking imaginatively, actively seeking out new points of view, problems and/or solution, being innovative and taking risks". Nationally and internationally, we see creativity regarded as a core 21 st century skill by business, government and education leaders [7-9].

Computer science and the design and creation of computational artefacts for end-users is by its' nature creative [10,11]. Unfortunately, many artefacts are created with an emphasis on business needs. It is imperative that the design of useful and usable artefacts take not only business but human needs into consideration [13]. In order to ensure these human needs are met, an empathetic approach to gathering user requirements is needed [14]. Empathy is also a vital characteristic of teachers in the creation of creative learning environments in the classroom [14-16]. Teacher empathy incorporates being mindful of learners personal and social circumstances, being compassionate and encouraging them to reach their potential [18]. The synergy of these characteristics is evident from the literature [18-21].

Teachers are central to the development of creativity in computer science students and as such their perceptions of the subject and its implementation are critical.

The aim of this paper is to investigate the use of design thinking within Computer Science initial teacher education to answer the following research question "What are the perceptions of the preservice teachers regarding the use of design thinking to foster creativity in computer science classrooms?". We will demonstrate, from our experiences, how pre-service teachers can use the design thinking approach to foster creativity in their learners.

The paper is organised as follows, Section 2 presents an overview of the design thinking process, how it relates to computer science education and its' ability to foster creativity; in Section 3, we describe the method and procedure of our research; Section 4 examines 
the findings of quantitative and qualitative data collected during the design thinking workshop; and finally, Section 5 discusses the implications of our research.

\section{DESIGN THINKING IN COMPUTER SCIENCE}

\subsection{Computer Science Pedagogy}

Given that computer science is largely problem driven, Constructionism and Problem-based learning are two learning theories long associated with teaching computer science [23]-[26], [27].

Constructionism is a learning theory which centres on the idea that students learn best in an environment where they are actively engaged in knowledge construction through the construction of a concrete artefact [26]. Therefore, a constructionist classroom should include student-centred interactive activities where students are given experiences that allow them to "hypothesize, predict, manipulate objects, pose questions, research, investigate, imagine, and invent" [28]. Another important tenet of constructionism is the idea that thinking and reflecting on what we do reinforces our learning [29].

In Problem-based learning (PBL), students are presented with an open-ended real-world problem that fosters their meta-cognitive skills of planning, brainstorming, active listening and reflection of learning amongst others [24].

Computer science is seen as a field that exhibits immense creativity from innovative hardware and software, such as, health monitoring devices and artificial intelligence [30], [31]. More recently, Romeike recognised the importance of three drivers for creativity in computer science education[32]. These were developed based on more general creative characteristics from the literature. They include the person, the environment and the process. According to the study, the person is concerned with motivation and engagement with the creation of useful software. The software design process and the use of building blocks to create new solutions to problems is associated with the process. Finally, the need for a creative environment that supports the creative process is required. It has been argued that creative computer science lessons greatly motivate and engage students and can overcome many negative associations with computer science in schools, such as, low motivation or retention [33].

\subsection{The Stanford Design Thinking Model}

Design Thinking is a human-centred approach to solving real-world complex problems [34]-[36] much like the learning theories linked with computer science education. The Design thinking process takes the designer through the following 5 stages or modes as seen in Figure 1 from Stanford Design Thinking Schools' Bootcamp Bootleg [37].

2.2.1 Empathise Stage. Empathising with your users is the first stage of the design thinking process [14]. It centres around knowing who your users are and exactly what they want. It requires the designer to immerse themselves in the problem using observation, empathy and questioning [35], [38]. Often designers are asked to solve problems that they lack experience in. Therefore, they must watch the users interacting within their environment

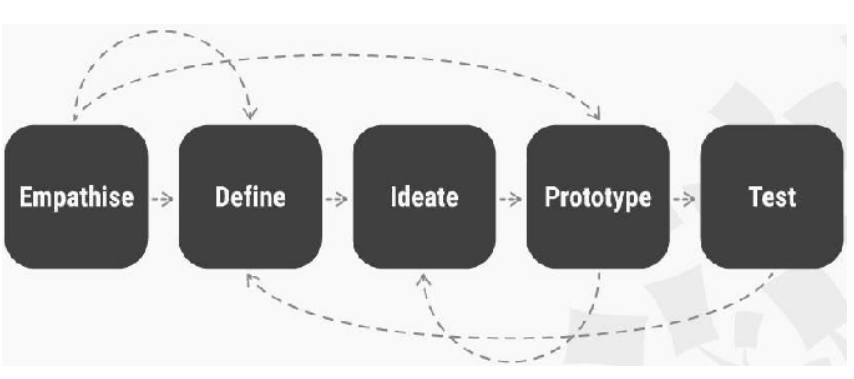

Figure 1: Stanford Design Thinking Model Stages [36]

to capture physical manifestations of their experience along with their thoughts and feelings which can be achieved using interviews [39].

2.2.2 Define Stage. Viewing the design problem from multiple perspectives in all its complexity occurs during the define stage [40]. The goals during this stage are to fully understand your users' needs and correctly frame your design challenge (IDEO, 2015). The Bootcamp Bootleg (2018) discusses the use of "How might we" statements to frame the design challenge. Using the "How Might We" technique is designed to "open the way for new ideas, acknowledges that we do not currently know the answer, and encourages a collaborative approach to solving it" [42]. If the How Might We is framed correctly, it should not suggest one specific solution but many diverse ones [43].

2.2.3 Ideate Stage. In the previous stage, the design problem has been defined. The Ideate stage is concerned with creating several possible solutions using brainstorming [22]. Choosing one of the How might we statements is a great starting point. Quantity and diversity are two important concepts when discussing the formation of ideas [43]. Idea generation and evaluation should be separated as much as possible at this stage to promote openness and encourage wild innovative ideas without judgement [39], [40].

2.2.4 Prototype Stage. In the prototyping stage, focus is on physically representing the best ideas created in the Ideate stage [39]. A "bias towards action", one of the design thinking mindsets, is central to this stage [37], [21]. Protypes can take on numerous different forms, such as, a storyboard, an object, an interface or simply a wall of post-it notes. The generation of several iterative disposable prototypes allows for the testing and refining of ideas in the final stage without investing a lot of resources [35]. The focus is not necessarily on the creation of the final product but to "prove and improve ideas and concepts" [38].

2.2.5 Test Stage. "Prototype as if you know you're right but test as if you know you're wrong." [37] Crucial to the success of your design is gathering feedback from the potential users. Through the process of user testing, designers can gain more knowledge and experience with the problem and potential solution [34], [38]. Redefinition of the problem and design may occur as this stage [40]. Although outlined in a linear fashion here, the different stages of design thinking are iterative by nature [34], [35], [40]. 


\subsection{The Benefits of Design Thinking for Computer Science Education}

Due to the current advancements in technology, computer science teachers will be responsible for enabling students to create innovative products which design thinking has been proven to facilitate. The post-primary computer science specification argues that design is "one of the key practices and principles of computer science" [1]. The concepts of user-centred design and the design process are embedded in the curriculum through the completion of team based applied learning tasks, one of which requires the student to develop an interactive website.

The development of these products will require the higher-order thinking skills of creativity and problem solving.

Alongside these skills, design thinking allows for self-awareness and persistence as the teacher must evaluate the ideas created and not attach to any one idea. This closely ties to the creativity fostering idea of experimentation and embracing failure that is found in computer science [32], [40].

Similar to Problem-based learning, the design thinking process begins with a real-world problem designed to foster experiential learning which allows the teacher to build on previous knowledge. This problem or scenario serves as the basis for learning in a classroom environment. Knowledge construction through the construction of a concrete artefact was found to be an effective methodology in constructionism theory [23], [26]. The use of a real-world problem has been found to increase student motivation and engagement within the classroom.

When creating computational artefacts, it is vital to fully understand a users' needs. During the first stage of design thinking, the designer must empathise with the user to facilitate definition of the correct problem which subsequently leads to the best solution.

The results of the Define stage is the creation of a set of How might we statements which define the problem statement. These statements are created from viewing the problem from multiple viewpoints and link with the idea of the constructionist classroom [26].

Another essential skill related to Problem Based Learning incorporated in the Ideate and Prototype stages of the design thinking approach is problem solving. The creation of several diverse ideas is facilitated through brainstorming which supports divergent and convergent thinking [34].

Looking more specifically at the skill of creativity, several studies have found an increase in creative confidence through the design thinking process. Kelley \& Kelly (2013) claims that it "relies on the natural and coachable human ability to be intuitive, to recognise patterns and to construct ideas that are emotionally meaningful as well as functional" [20]. Another study mentions "Trust in one's own creative skills" as a positive outcome of the design thinking process [21]. Research in the area of educational problems of practise [40], has also found strong links between design thinking and creativity.

In the area of computer science specifically, studies have shown that using the design thinking process enhances creativity, engagement and empathy [12], [14], [44], [45]. One study conducted in mobile application development found evidence that design thinking allowed teachers to understand "how the users think, do, dream and what are their real needs" while brainstorming allowed for collaboration which helped with interactivity and idea creation [14]. Also noted in this study was the value of using the design thinking process in mobile application development. Following on from this study, Pham et al found indications of a positive change in perspective on the human-centred approach in mobile application development having taken part in a design thinking workshop (Pham et al., 2018).

Lastly, group work, a key principle of Problem Based Learning, facilitated in Design Thinking has been found to increase engagement in the problem solution.

The studies presented thus far provide evidence that indicates that creativity and problem solving, all skills necessary for computer science, are enhanced in design thinking.

\section{METHOD}

This study examines the relationship between using the design thinking process as a teaching approach with pre-service teachers in web application development and its' ability to foster creativity and problem solving.

\subsection{Context and Participants}

The workshops, which were compulsory, took place with 16 preservice teachers undertaking an initial teacher education degree in Mathematics and Computer Science education at a university in Ireland. The workshops were part of an education module engaging students critically and reflectively in topics associated with essential teaching and learning skills. The workshops were designed to bring the pre-service teachers through the five stages of the Design Thinking process based on the Stanford Virtual Crash course. The workshops were delivered over four hours in total broken up into a two-hour workshop each week for two weeks. The artefacts created during the workshops did not contribute towards their final grade.

The classroom used allowed for a flexible design thinking workspace where the pre-service teachers could move around. They were also given materials including large sheets of paper, markers, stickers, post-it notes to enable them to be creative in their design.

\subsection{Real World Design Challenge}

At the beginning of the workshop, the teachers were introduced to the five stages of the design thinking process, the benefits of design thinking, a design thinking example and the methods used as outlined in section 2.2. In order to help the teachers feel comfortable, a short ten-minute creative exercise was undertaken before the realworld design challenge. This exercise asked the teachers to ideate and write or sketch out what their dream college looked like. This was a low risk fun activity that let the teachers give their opinions on a familiar topic.

Once finished with the exercise, the real-world design challenge was presented. For maximum engagement with the methodology, the pre-service teachers were given a choice of two challenges that they would be familiar with. The first was "The transition from post-primary to third level" and the other option was "The 1 st year college experience". As the pre-service teachers were in the first year of their studies, these options were chosen as they were decidedly relevant. The students were made aware that the 
eventual solution should be a web application that other first year students could use.

3.2.1 Empathise Stage. The pre-service teachers started the Empathise stage working individually to create relevant interview questions. Their task was to seek stories from their partners. It was important that these questions allowed their partner to talk through a tangible experience which would allow them to consider what they thought, felt and what they did in the situation.

Examples of sample questions that the teachers were given.

- Could you tell me about...?

- What's the worst experience you've had?

In groups of 3 and 4 , the pre-service teachers were asked to interview one of the other teachers for 15 minutes. Initially, one pre-service teacher interviewed another pre-service teacher while the third took a note of the answers. This is important as it is not possible to take notes and actively listen simultaneously. They then swapped around so that each pre-service teacher had experienced each role. The pre-service teachers were directed to focus on the interviewee with a view to seeking stories and points of view. They were advised to pay attention to nonverbal cues as sometimes body language or lack of information can provide valuable information.

As soon as the interviews were completed, the pre-service teachers were asked to create an empathy map based on the answers and observations they had collected from their interviews.

3.2.2 Define Stage. Next, the pre-service teachers moved on to stage 2 , where they were invited to narrow down the general design challenge into a more specific problem statement using the information collected in the previous stage. They were instructed to generate multiple "How might we...?" statements that would allow them to reframe the problem definition and come up with innovative ideas in the Ideate stage.

Examples of sample questions that the teachers were given.

- How might we make the transition easier for students who are moving away from home?

- How might we better prepare students before they start college?

The pre-service teachers were encouraged to review their How Might We question and ask themselves if it was both narrow enough to know where to start brainstorming, but also enable enough freedom to give room to explore unusual ideas. [37]

Some example How Might We's developed by the teachers during this stage were:

- "How might we make it easier to meet new people?"

- "How might we find more people with the same interests?"

3.2.3 Ideate Stage. Generation of Ideas is the focus of stage 3. One "How might we" statement was chosen to brainstorm on. During this activity, the pre-service teachers were urged to generate lots of ideas without judgement. They were encouraged to listen to each other and to build on the ideas of others.

Some examples of ideas generated at this stage were:

- Upon arrival at college, students take a survey to identify their interests and are encouraged to join or create new clubs or societies

- Create more informal hangout areas
These ideas became the input into the next stage, prototyping.

3.2.4 Prototype Stage. As the first activity in stage 4, the preservice teachers were asked to "create a story" from the ideas generated in the Ideate stage. The task was to tell the story of their ideas from the future or describe their idea as if it were published on the college website. "Sketch it Out" was the next activity where the pre-service teachers were asked to choose one idea and flesh it out into a web application using a prototype form that suited their needs. Due to the nature of the solution, they created mock-up screens of their web application using simple sketches on paper.

3.2.5 Test Stage. The final stage allowed the groups to test their idea with another group to get feedback in order to refine their prototype/idea. This allowed them to share their idea with others and discuss how to further refine it. They were interested in what worked and what they could improve on in their design. Finally, they reflected on their designs and the feedback to see if it led to any new questions or ideas. They were encouraged to use the "I like/I wish/What if" tool from the Bootcamp Bootleg in order to ensure that feedback was constructive and not too personal.

After finishing the final stage, the pre-service teachers were asked to report their perceptions of the approach through a questionnaire and reflections.

\subsection{Data Collection}

This study used a combination of qualitative and quantitative analysis tools through teacher reflections and a questionnaire.

Quantitative data collection was completed using a questionnaire adapted from one previously validated by Noweski et al [46]. The questionnaire consisted of Likert scale questions seeking to find the answers to the following four research questions:

1. Do pre-service teachers view design thinking as a good approach to teaching computer science concepts in postprimary level?

2. Do pre-service teachers view design thinking as a good approach to the creation of computational artefacts in computer science at post-primary level?

3. Do pre-service teachers view design thinking as an engaging, motivating approach to teaching computer science concepts at post-primary level?

4. Would pre-service teachers use the design thinking approach in their own classrooms?

In addition, teachers were asked to reflect on the design thinking workshops from an educational viewpoint.

\section{ANALYSIS AND DISCUSSION}

On completion of the questionnaire, data analysis was completed to ascertain the pre-service teachers' perceptions of design thinking with reference to the four research questions outlined in section four and its' ability to foster creativity. Figure 2 presents the findings of a subset of the questions.

Our initial analysis of the data was completed through the lens of the four original research questions.

Firstly, we explored the findings of the pre-service teachers' perceptions of whether design thinking is a good approach to teaching computer science. The data provides convincing evidence of this 
with $81 \%$ of the teachers believing that it would be useful when creating a website or web application and one pre-service teacher summing it up as follows:

Different aspects in math may require this design thinking to be applied but I think it will be especially beneficial in computer science classes.

This strengthens the previous evidence from other studies undertaken [12], [14], [44].

Along similar lines, our second research question seeks to understand whether the pre-service teachers believed that design thinking was a good approach to use to foster creativity in the creation of a web application as has been shown in numerous studies [12], [14], [44]. A strong association is shown here with $81 \%$ of the pre-service teachers believing that it would be useful when creating a website or web application. In the words of one teacher:

Although at this point, we aren't fully aware of what the curriculum will be for computer science I can imagine it will include the development of some sort of program or webpage in which this design process will be extremely useful.

Previous research [14] has shown that motivation and engagement is high during a design thinking session. Regarding the view of design thinking as engaging and motivating as set out in our third research question, our pre-service teachers teachers supported previous findings with $62 \%$ of Pre-Service teachers believing that our youth would be more engaged and $69 \%$ believing that our youth would be more motivated if there were occasional Design thinking projects at school. This is summed up in a comment from one of the pre-service teachers:

This week's session on design thinking was highly engaging and thought provoking.

Our final question seeks to determine the pre-service teachers' overall view of the value of design thinking. Consistent with research on design thinking in other fields [40], [43] our data provided preliminary evidence of the teachers perceptions of its 'value with $62 \%$ of the pre-service teachers agreeing that they would definitely carry out a Design Thinking project if they had a chance if they were working with kids in school and one teacher stating:

By caring out this task it has made me think of when and where I can apply this design thinking in my classroom and with my future students.

Finally, we analysed the relationship between creativity and design thinking. This claim has been proven extensively in the literature. With certain studies [47] claiming that empathy is a core skill needed to create artefacts that satisfy another's needs. Brainstorming by its nature promotes creativity through the use of divergent and convergent thinking and facilitates the creation of an abundance of different ideas. The idea of risk taking or experimentation, central to creativity [20], [47] is closely tied to the ideate and prototyping stages of the design thinking process and fostering creativity in computer science [32]. The pre-service teachers felt a clear link between creativity and design thinking with one pre-service teacher mentioning that:

During the past two weeks in this class, we thought and reflected on creative thinking. Firstly, we were

\begin{tabular}{|c|c|c|c|c|c|}
\hline Survey Question & $\begin{array}{l}\text { Strongly } \\
\text { Agree }\end{array}$ & Agree & $\begin{array}{l}\text { Neither } \\
\text { Agree not } \\
\text { Disagree }\end{array}$ & Disagree & $\begin{array}{l}\text { Strongly } \\
\text { Disagree }\end{array}$ \\
\hline $\begin{array}{l}\text { I believe that Design Thinking would be } \\
\text { useful when creating a website or web } \\
\text { application. }\end{array}$ & $\begin{array}{c}5 / 16 \\
31.3 \%\end{array}$ & $\begin{array}{l}8 / 16 \\
50 \%\end{array}$ & $\begin{array}{l}1 / 16 \\
6.3 \%\end{array}$ & $\begin{array}{c}0 / 16 \\
0 \%\end{array}$ & $\begin{array}{c}2 / 16 \\
12.5 \%\end{array}$ \\
\hline $\begin{array}{l}\text { I believe that Design Thinking would be } \\
\text { useful for educators. }\end{array}$ & $\begin{array}{c}2 / 16 \\
12.5 \%\end{array}$ & $\begin{array}{c}7 / 16 \\
\mathbf{4 3 . 8 \%}\end{array}$ & $\begin{array}{l}4 / 16 \\
25 \%\end{array}$ & $\begin{array}{l}1 / 16 \\
6.3 \%\end{array}$ & $\begin{array}{l}2 / 16 \\
12.5 \%\end{array}$ \\
\hline $\begin{array}{l}\text { I believe that our youth would be more } \\
\text { motivated if there were occasional } \\
\text { Design thinking projects at school. }\end{array}$ & $\begin{array}{c}3 / 16 \\
18.8 \%\end{array}$ & $\begin{array}{l}8 / 16 \\
50 \%\end{array}$ & $\begin{array}{l}4 / 16 \\
25 \%\end{array}$ & $\begin{array}{l}1 / 16 \\
6.3 \%\end{array}$ & $\begin{array}{c}0 / 16 \\
0 \%\end{array}$ \\
\hline $\begin{array}{l}\text { I believe that our youth would be more } \\
\text { engaged if there were occasional Design } \\
\text { thinking projects at school. }\end{array}$ & $\begin{array}{l}7 / 16 \\
43.8 \%\end{array}$ & $\begin{array}{c}3 / 16 \\
18.8 \%\end{array}$ & $\begin{array}{c}5 / 16 \\
31.3 \%\end{array}$ & $\begin{array}{l}1 / 16 \\
6.3 \%\end{array}$ & $\begin{array}{c}0 / 16 \\
0 \%\end{array}$ \\
\hline $\begin{array}{l}\text { I believe that our youth would be more } \\
\text { socially competent if there were } \\
\text { occasional Design thinking projects at } \\
\text { school. }\end{array}$ & $\begin{array}{c}3 / 16 \\
18.8 \%\end{array}$ & $\begin{array}{c}6 / 16 \\
37.5 \%\end{array}$ & $\begin{array}{l}4 / 16 \\
25 \%\end{array}$ & $\begin{array}{r}3 / 16 \\
18.8 \%\end{array}$ & $\begin{array}{c}0 / 16 \\
0 \%\end{array}$ \\
\hline $\begin{array}{l}\text { If I was working with kids in school now. } \\
\text { I would definitely carry out a Design } \\
\text { Thinking project if I had a chance. }\end{array}$ & $\begin{array}{l}4 / 16 \\
25 \%\end{array}$ & $\begin{array}{c}6 / 16 \\
37.5 \%\end{array}$ & $\begin{array}{c}2 / 16 \\
12.5 \%\end{array}$ & $\begin{array}{c}2 / 16 \\
12.5 \%\end{array}$ & $\begin{array}{c}2 / 16 \\
12.5 \%\end{array}$ \\
\hline
\end{tabular}

Figure 2: Subset of Quantitative Data Analysed

asked to describe and draw our dream college. This allowed us to express our creative thinking and was a way to begin our design thinking.

While another observed that:

The design thinking process is used in everyday business and is very effective in creating solutions to modern everyday problems.

\section{CONCLUSION AND RECOMMENDATIONS}

With the introduction of computer science at post-primary level in many countries, CS teachers will be tasked with the responsibility of fostering their students' creativity and problem-solving skills using innovative and engaging approaches. One such approach used by many companies and educational institutions is the design thinking process. This process encompasses a human-centered approach to problem solving and solution creation, where the core components and values consist of a bias towards doing and making, a focus on human values, embracing experimentation and radical collaboration. These mindsets are closely related to the computer science pedagogies of constructionism and problem-based learning.

The aim of this article was to present an evaluation of the design thinking process with a cohort of pre-service CS teachers with a view to understanding their perceptions of its effect on creativity and problem solving. This exploratory study demonstrated that the design thinking process was extremely beneficial when teaching CS concepts such as web application development, with this group of pre-service Computer Science and Mathematics teachers. The pivotal role of creativity in design thinking and its relevance to CS was established and pre-service teachers reported positive views on the completion of the design thinking workshops. The potential for increased motivation and engagement within the computer science classroom when using the process was evident in the results presented. Furthermore, a strong link between the design thinking process and increased empathy was identified.

The study is not without limitations and a primary limitation is the narrow focus, with such a small number of participants from 
one specific initial teacher education programme and the time constraints which had to be accommodated. Generalisations are not acceptable, however the results gained from the study can effectively point out possible avenues which require further investigation and validation with larger groups of pre-service teachers. Future research will be carried out in the next academic year investigating the role empathy plays in creativity and CS teacher education.

While this study demonstrates the potential for twentieth-first century skill development at post-primary in Ireland, more research is needed to confirm the positive effects of design thinking in the computer science classroom.

\section{REFERENCES}

[1] "NCCA Specification for Leaving Certificate." Accessed: Nov. 15, 2019. [Online] Available: https://curriculumonline.ie/getmedia/d73af6e3-b4e5-4edb-a5146383e2306a4b/16626-NCCA-Specification-for-Leaving-Certificate-CS-WEBv4.pdf.

[2] N. Keane and C. McInerney, "Report on the provision of courses in computer science in upper second level education internationally," Rep. Comm. Natl. Counc. Curric. Assess., 2017.

[3] K. Quille and S. Bergin, "Promoting a Growth Mindset in CS1: Does One Size Fit All? A Pilot Study," in Proceedings of the 2020 ACM Conference on Innovation and Technology in Computer Science Education, 2020, pp. 12-18.

[4] O. McGarr and K. Johnston, "Curricular responses to Computer Science provision in schools: current provision and alternative possibilities," Curric. f., 2020.

[5] C. Connolly, "Computer science at post primary in Ireland: specification design and key skills integration," in Proceedings of the 13th Workshop in Primary and Secondary Computing Education, 2018, pp. 1-2.

[6] P. Mishra, A. Yadav, D.-P. R. Group, and others, "Rethinking technology \& creativity in the 21st century," TechTrends, vol. 57, no. 3, pp. 10-14, 2013.

[7] M. Resnick et al., "Scratch: Programming for all.," Commun Acm, vol. 52, no. 11, pp. 60-67, 2009

[8] "Action Plan for Education." Accessed: Jul. 09, 2018. [Online]. Available: https://www.education.ie/en/Publications/Corporate-Reports/StrategyStatement/action-plan-for-education-2018.pdf.

[9] N. (National C. for Curriculum and Assessment), Senior Cycle Key Skills Framework. NCCA Dublin, 2009.

[10] World Economic Forum, "The future of jobs report 2018," 2018.

[11] R. Romeike, "The Contribution of Computer Science Education in a Creative Society," in IFIP World Computer Congress, TC 3, 2008, pp. 237-244.

[12] M. D. DeSchryver and A. Yadav, "Creative and computational thinking in the context of new literacies: Working with teachers to scaffold complex technologymediated approaches to teaching and learning," f. Technol. Teach. Educ., vol. 23 , no. 3, pp. 411-431, 2015.

[13] P. Zhang, J. Carey, D. Te'eni, and M. Tremaine, "Integrating Human-Computer In teraction Development into the Systems Development Life Cycle: A Methodology, Commun. Assoc. Inf. Syst., vol. 15, 2005, doi: 10.17705/1CAIS.01529.

[14] N. M. C. Valentim, W. Silva, and T. Conte, "The students' perspectives on applying design thinking for the design of mobile applications," in Proceedings of the 39th International Conference on Software Engineering: Software Engineering and Education Track, 2017, pp. 77-86.

[15] D. Davies, D. Jindal-Snape, C. Collier, R. Digby, P. Hay, and A. Howe, "Creative learning environments in education-A systematic literature review," Think. Ski. Creat., vol. 8, pp. 80-91, 2013, doi: https://doi.org/10.1016/j.tsc.2012.07.004.

[16] R. C. Reilly, F. Lilly, G. Bramwell, and N. Kronish, "A synthesis of research concerning creative teachers in a Canadian context," Teach. Teach. Educ., vol. 27, no. 3, pp. 533-542, 2011.

[17] K. Soh, "Fostering student creativity through teacher behaviors," Think. Ski. Creat. vol. 23, pp. 58-66, 2017.

[18] S. Meyers, K. Rowell, M. Wells, and B. C. Smith, "Teacher Empathy: A Model of Empathy for Teaching for Student Success," Coll. Teach., pp. 1-9, 2019.

[19] T. Kelley and D. Kelley, "Reclaim your creative confidence.," Harv. Bus. Rev., vol. 90 , no. 12, pp. $115-8,2012$.
[20] T. Kelley and D. Kelley, Creative confidence: Unleashing the creative potential within us all. Currency, 2013.

[21] I. Rauth, E. Köppen, B. Jobst, C. Meinel, and others, "Design thinking: an educational model towards creative confidence," 2010.

[22] R. Steinbeck, "Building creative competence in globally distributed courses through design thinking," Rev. Comun., vol. 19, no. 37, pp. 27-34, 2011.

[23] I. Harel and S. Papert, "Software design as a learning environment," Interact. Learn. Environ., vol. 1, no. 1, pp. 1-32, 1990.

[24] J. Kay et al., "Problem-Based Learning for Foundation Computer Science Courses," Comput. Sci. Educ., vol. 10, no. 2, pp. 109-128, Aug. 2000, doi: 10.1076/08993408(200008)10:2;1-C;FT109.

[25] M. J. O'Grady, "Practical problem-based learning in computing education," ACM Trans. Comput. Educ. TOCE, vol. 12, no. 3, pp. 1-16, 2012.

[26] S. Papert and I. Harel, "Situating constructionism," Constructionism, vol. 36, no. 2, pp. 1-11, 1991.

[27] J. R. Byrne, L. Fisher, and B. Tangney, "Empowering teachers to teach CSExploring a social constructivist approach for CS CPD, using the Bridge21 model," in 2015 IEEE Frontiers in Education Conference (FIE), 2015, pp. 1-9.

[28] A. J. Gray, Constructivist teaching and learning. Saskatchewan School Trustees Association, 1997.

[29] S. Papert, "Teaching children thinking," Program. Learn. Educ. Technol., vol. 9, no. 5, pp. 245-255, 1972.

[30] M. Chan, D. Estève, J.-Y. Fourniols, C. Escriba, and E. Campo, "Smart wearable systems: Current status and future challenges," Artif. Intell. Med., vol. 56, no. 3, pp. 137-156, 2012.

[31] D. Saunders and P. Thagard, "Creativity in computer science," Creat. Domains Faces Muse, pp. 153-167, 2005.

[32] R. Romeike, "Three drivers for creativity in computer science education," Proc Inform. Math. ICT A'golden Triangle' Boston USA, 2007.

[33] R. Romeike, "Applying creativity in CS high school education: criteria, teaching example and evaluation," in Proceedings of the Seventh Baltic Sea Conference on Computing Education Research-Volume 88, 2007, pp. 87-96.

[34] W. Brenner, F. Uebernickel, and T. Abrell, "Design thinking as mindset, process, and toolbox," in Design thinking for innovation, Springer, 2016, pp. 3-21.

[35] T. Brown and B. Katz, "Change by design," f. Prod. Innov. Manag., vol. 28, no. 3, pp. 381-383, 2011.

[36] R. Dam and T. Siang, "5 Stages in the Design Thinking Process," The Interaction Design Foundation, 2019. https://www.interaction-design.org//literature/article/5stages-in-the-design-thinking-process (accessed Nov. 15, 2019).

[37] H. Plattner, "Bootcamp bootleg," Des. Sch. Stanf. Palo Alto, 2010.

[38] C. Noweski, A. Scheer, N. Büttner, J. von Thienen, J. Erdmann, and C. Meinel, "Towards a paradigm shift in education practice: Developing twenty-first century skills with design thinking," in Design thinking research, Springer, 2012, pp. 71-94.

[39] T. Brown and J. Wyatt, "Design thinking for social innovation," Dev. Outreach, vol. 12 , no. 1 , pp. $29-43,2010$

[40] D. Henriksen, C. Richardson, and R. Mehta, "Design thinking: A creative approach to educational problems of practice," Think. Ski. Creat., vol. 26, pp. 140-153, 2017.

[41] IDEO. (Firma comercial), The field guide to human-centered design. Design Kit, 2015.

[42] R. Dam and T. Siang, "Define and frame your design challenge by creating your point of view and ask 'How might we.,"' URL Httpswww Interact.Des. Orgliteraturearticledefine-Frame-Your-Des.-Challengeby-Creat.-Your-PointView-Ask-Might-We, 2017.

[43] R. Glen, C. Suciu, C. C. Baughn, and R. Anson, "Teaching design thinking in business schools," Int. f. Manag. Educ., vol. 13, no. 2, pp. 182-192, 2015.

[44] Y. D. Pham, D. Fucci, and W. Maalej, "A first implementation of a design thinking workshop during a mobile app development course project," in Proceedings of the 2nd International Workshop on Software Engineering Education for Millennials, 2018, pp. 56-63.

[45] T. Lindberg, E. Köppen, I. Rauth, and C. Meinel, "On the perception, adoption and implementation of design thinking in the IT industry," in Design thinking research, Springer, 2012, pp. 229-240.

[46] A. Scheer, C. Noweski, and C. Meinel, "Transforming constructivist learning into action: Design thinking in education," Des. Technol. Educ. Int. f., vol. 17, no. 3, 2012.

[47] R. Root-Bernstein and M. Root-Bernstein, Sparks of genius: The 13 thinking tools of the world's most creative people. $\mathrm{HMH}, 2013$. 